\title{
Bond strengths of various resin cements to different ceramics
}

\section{David Cardoso Sandes FARIAS(a) Letícia Machado GONÇALVES(b) Ricardo WALTER ${ }^{(c)}$ \\ Yunro CHUNG(d) \\ Markus Bernhard BLATZ(e)}

(a) Universidade CEUMA, Department of Dentistry, São Luís, MA, Brazil.

(b) Universidade CEUMA, Postgraduate Program in Dentistry, São Luís, MA, Brazil.

(c) University of North Carolina, Department of Operative Dentistry, Chapel Hill, NC, USA.

(d) Arizona State University, Department of Biomedical Informatics, Arizona Tempe, AZ, USA.

(e) University of Pennsylvania, School of Dental Medicine, Department of Preventive and Restorative Sciences, Philadelphia, PA, USA.

Declaration of Interests: The authors certify that they have no commercial or associative interest that represents a conflict of interest in connection with the manuscript.

\section{Corresponding Author:}

David Cardoso Sandes Farias

E-mail: davidcsfarias@hotmail.com

htrps://doi.org/10.1590/1807-3107bor-2019.vol33.0095

Submitted: April 21, 2019

Accepted for publication: September 1, 2019

Last revision: September 9, 2019
Abstract: This study evaluates the shear bond strength (SBS) of various resin cements to different ceramics. Composite resin cylinders of Z100 were fabricated and cemented to disks of feldspathic ceramic (Creation), leucite-reinforced feldspathic ceramic (Empress I), and densely sintered aluminum oxide ceramic (Procera AllCeram) using five resin cements: Panavia F (PAN), RelyX ARC (ARC), RelyX Unicem (RXU), RelyX Veneer, and Variolink II. SBS was measured after three days of water storage (baseline) and after artificial aging (180 days of water storage along with 12,000 thermal cycles). Failure mode of fractured specimens also was evaluated. Data were analyzed with Kruskal-Wallis and Mann-Whitney tests $(\alpha=0.05)$. RXU showed 1) the lowest baseline median SBS to feldspathic ceramic, which was not statistically different from PAN; 2) the lowest median baseline SBS to leucite-reinforced feldspathic and densely sintered aluminum-oxide ceramics. All cements performed similarly after aging, except for ARC (median 0.0 MPa) and PAN (median $16.2 \mathrm{MPa}$ ) in the densely sintered aluminum-oxide ceramic group. Resin cements perform differently when bonded to different ceramic substrates. While all test resin cements worked similarly in the long-term to feldspathic and leucite-reinforced feldspathic ceramics, only the MDP-containing resin cement provided durable bonds to densely sintered aluminum-oxide ceramic.

Keywords: Resin Cements; Ceramics; Aging; Aluminum Oxide; Shear Strength.

\section{Introduction}

Recent progress in technology and research related to new dental materials have resulted in an increasing number of all-ceramic materials and systems commercially available for clinical use. ${ }^{1}$ In addition to feldspathic porcelain, machinable glass ceramic, glass-infiltrated alumina ceramic, densely sintered high-purity alumina ceramic, and zirconia ceramic are widely used in clinical practice. Clinical success of such restorations relies on a strong and durable resin bond to the restorative material and supporting tooth structures. A strong, durable resin bond provides high retention, ${ }^{2}$ improves marginal adaptation and prevents microleakage, ${ }^{3}$ and increases fracture resistance of the restored tooth and the restoration. ${ }^{4}$ 
Bonding to ceramics is facilitated by micromechanical interlocking and formation of chemical bonds between resin cements and ceramic substrates. ${ }^{5}$ To promote such interactions, surface modification by etching with hydrofluoric acid and subsequent silanization of the ceramic has been advocated for use with silica-based ceramics. ${ }^{6,7}$ Selective use of hydrofluoric acid dissolves the glassy matrix of silica-based ceramics producing a porous surface. That modified surface has increased surface area and may allow for better resin cement penetration. ${ }^{8,9}$

Such procedure yields adequate micromechanical bonding, whereas subsequent silanization of the etched ceramic facilitates chemical bonding between the resin cement and ceramic..$^{10}$ After silanization, the created bifunctional silane layer is capable of chemically bonding to the hydrolyzed silicon dioxide on the ceramic surface and copolymerizing with the adhesive resin through its methacrylate-containing group. ${ }^{10,11}$ Meanwhile, hydrofluoric acid etching and silanization of aluminum- or zirconium-oxide ceramics are not reliable treatments. Such substrates do not contain the silicon oxide phase, which makes the reaction between the hydrofluoric acid and glass in the ceramic possible, ${ }^{12}$ and may require alternative mechanical and chemical surface treatment techniques to achieve reliable long-term resin-ceramic bonding., ${ }^{5,13}$

Various techniques have been investigated in an attempt to roughen and activate the surface of oxide ceramics in order to improve bonding. Studies have shown the positive effect of airborne particle abrasion when used with silica coating and silanization, ${ }^{14}$ and when followed by a ceramic primer in bonding to oxide ceramics. ${ }^{15}$ Airborne particle abrasion of oxide ceramics can be accomplished with different $\mathrm{Al}_{2} \mathrm{O}_{3}$ particle sizes and has been reported to increase the surface roughness, thereby increasing mechanical retention. ${ }^{5,16,17}$ It is a practical and cost effective method to clean and activate the surface of high-strength ceramics prior to bonding, and can be easily performed chairside. ${ }^{5,14,18}$ Yet, the effects of airborne particle abrasion on bonding to high-strength ceramics are discussed controversially as crack development potentially may occur, weakening the ceramic substrate. ${ }^{16,19}$
On the other hand, it is well accepted that airborne particle abrasion/silica coating followed by silanization improves bonding of resin cements to high-strength ceramics without any damage. ${ }^{20,21}$ The process of airborne particle abrasion with alumina particles coated with silica leaves the ceramic surface embedded with silica particles, which makes the chemically modified surface more reactive to bonding. ${ }^{14,22}$ Yet, bonding to airborne particle abrasion/silica coated-treated oxide ceramics seems to suffer degradation over time. ${ }^{7,23}$ Likewise, reduction in bond strengths over time may occur when the oxide surface is treated with a phosphate monomer-containing primer (after airborne particle abrasion only). ${ }^{24}$

Used with any surface preparation protocol (airborne particle abrasion/silica coating followed by silane agent or airborne particle abrasion followed by phosphate monomer-containing primer in oxide ceramics, or hydrofluoric acid followed by silane agent in silica-based ceramics), resin cements offer the advantage of sealing the created internal surface roughness, which significantly strengthens and improves the longevity of restorations. ${ }^{25}$ In that regard, self-adhesive resin cements, which have been introduced to simplify the application steps and minimize the time consumed during bonding procedures, can be utilized. According to the manufacturers, no pretreatment is necessary, such as etching, priming, bonding or silanization, on the enamel, dentin, or ceramic substrate when using self-adhesive cements. Some of those single-step resin cements contain functionalized monomers of phosphate groups and multifunctional acid methacrylates that are claimed to react simultaneously with the calcium ions of hydroxyapatite ${ }^{26}$ and the ceramic surface. ${ }^{27}$ In vitro bonding studies have shown positive results for self-adhesive resin cements when applied to highstrength aluminum-oxide, ${ }^{28,29}$ leucite-reinforced, ${ }^{27}$ and lithium disilicate ceramics. ${ }^{30}$

Despite the available literature on the effects of surface modification techniques and the use of self-adhesive resin cements in ceramics, limited information is available on bond strengths of selfadhesive resin cements to different ceramics after 
artificial aging. Therefore, the purpose of this study was to evaluate the shear bond strength (SBS) of RelyX Unicem (RXU, 3M ESPE, St. Paul, USA) to various ceramics after thermocycling. Four commercially available resin cements were used for comparison. It was hypothesized that the SBS of RXU to various ceramics would not be statistically different from that of the other resin cements and that it would not be affected by thermocycling.

\section{Methodology}

Two hundred and twenty ceramic specimens were fabricated for the study. Those were 80 feldspathic ceramic (Creation, Jenson Industries,
North Haven, USA), as used for porcelain veneers; 80 leucite-reinforced feldspathic ceramic (Empress I, Ivoclar Vivadent, Schaan, Liechtenstein), as used for all-ceramic restorations; and 60 densely sintered aluminum-oxide ceramic (Procera AllCeram; Nobel Biocare, Gothenburg, Sweden), as used for high-strength all-ceramic restorations. Resin cement systems used are listed in Table 1 . The ceramic specimens were randomly assigned into groups of 20 according to Table 2. Subgroups of 10 specimens were either stored in distilled water for 3 days or thermocycled.

Specimens with dimensions of $10-\mathrm{mm} \times 10-\mathrm{mm}$ x 2-mm were prepared and polished with 1,000-grit silicon carbide abrasive paper to obtain a standardized

Table 1. Resin cement systems used according to manufacturer's instructions.

\begin{tabular}{|c|c|c|c|}
\hline Resin cement & Type & Manufacturer & Composition \\
\hline $\begin{array}{l}\text { RelyX Unicem (Clicker } \\
\text { dispenser) }\end{array}$ & $\begin{array}{l}\text { Self-adhesive dual-curing } \\
\text { resin cement }\end{array}$ & 3M ESPE, St. Paul,MN, USA & $\begin{array}{c}\text { Base: glass fiber, methacrylate phosphoric acid esters, } \\
\text { dimethacrylates, silanated silica, sodium persulfate } \\
\text { Catalyst: glass fiber, dimethacrylates, silanated silica, } \\
\text { p-tolvene sodium sulfate, calcium hydroxide }\end{array}$ \\
\hline \multirow{2}{*}{$\begin{array}{l}\text { RelyX ARC (Clicker } \\
\text { dispenser) }\end{array}$} & Conventional & \multirow{2}{*}{ 3M ESPE, St. Paul,MN, USA } & $\begin{array}{l}\text { Paste A: Bis-GMA, TEGDMA, Silane treated } \\
\text { silica, functionalized dimethacrylate polymer, } \\
\text { 2-benzotriazolyl-4methylphenol, } \\
\text { 4-(Dimethylamino)-Benzeneethanol. }\end{array}$ \\
\hline & dual-curing resin cement & & $\begin{array}{c}\text { Paste B: Silane treated ceramic, TEGDMA, Bis-GMA, } \\
\text { Silane treated silica, functionalized dimethacrylate } \\
\text { polymer, 2-benzotriazolyl-4methylphenol, } \\
\text { benzoyl peroxide }\end{array}$ \\
\hline RelyX Veneer & $\begin{array}{l}\text { Conventional } \\
\text { dual-curing resin cement }\end{array}$ & & $\begin{array}{c}\text { Bis-GMA, TEGDMA, zirconia/silica filler, pigments, } \\
\text { photoinitiator }\end{array}$ \\
\hline Adper Single Bond 2 & Bonding agent & & $\begin{array}{c}\text { Bis-GMA, HEMA, UDMA, dimethacrylates, ethanol, } \\
\text { water, camphorquinone, acid compolymer, silica } \\
\text { particles }\end{array}$ \\
\hline RelyX Ceramic Primer & Silane & & $\begin{array}{l}\text { Ethyl alcohol, water, } \\
\text { 3- methacryloyloxypropyltrimethoxy-silane }\end{array}$ \\
\hline Panavia $F$ (2 pastes) & $\begin{array}{l}\text { Self-adhesive dual-curing } \\
\text { resin cement }\end{array}$ & $\begin{array}{l}\text { Kuraray Noritake Dental Inc., } \\
\text { Tokyo, Japan }\end{array}$ & $\begin{array}{c}\text { Paste A: MDP, methacrylate monomer, filler, initiator } \\
\text { Paste B: methacrylate monomer, filler, NaF, initiator, } \\
\text { pigment }\end{array}$ \\
\hline \multirow{2}{*}{ ED Primer } & \multirow{2}{*}{ Silane } & \multirow{4}{*}{$\begin{array}{l}\text { Ivoclar Vivadent, Schaan, } \\
\text { Liechtenstein }\end{array}$} & $\begin{array}{c}\text { Primer A: HEMA, 10-MDP, 5-NMSA, water, } \\
\text { accelerator }\end{array}$ \\
\hline & & & $\begin{array}{c}\text { Primer B: 5-NMSA, accelerator, water, sodium } \\
\text { benzene, sulphinate }\end{array}$ \\
\hline \multirow{2}{*}{ Variolink II } & Conventional & & $\begin{array}{c}\text { Base: Bis-GMA, TEGDMA, UDMA, fillers, ytterbium } \\
\text { trifluoride, stabilizers, pigments }\end{array}$ \\
\hline & dual-curing resin cement & & $\begin{array}{c}\text { Catalyst: Bis-GMA, TEGDMA, UDMA, benzoyl } \\
\text { peroxide }\end{array}$ \\
\hline Heliobond & Bonding agent & & Bis-GMA, TEGDMA, initiators, stabilisers \\
\hline Monobond S & Silane & & $\begin{array}{c}\text { 3-methacryloxypropyl-trimethoxysilane } 1 \% \text {, water and } \\
\text { ethanol } 99 \% \text {, acetic acid }\end{array}$ \\
\hline
\end{tabular}


Table 2. Early and late shear bond strength (SBS) values (MPa).

\begin{tabular}{|c|c|c|c|c|c|}
\hline \multirow{2}{*}{ Group } & \multicolumn{2}{|c|}{ Early SBS } & \multirow[t]{2}{*}{$P$ value early vs. late* } & \multicolumn{2}{|c|}{ Late SBS } \\
\hline & Medians & $25^{\text {th }} / 75^{\text {th }}$ percentiles & & Medians & 25th/75th percentiles \\
\hline \multicolumn{6}{|c|}{ Feldspathic ceramic } \\
\hline VAR & $23.5^{\circ}$ & $22.2 / 30.4$ & $p=1.0000$ & $23.9^{a}$ & $13.9 / 31.1$ \\
\hline VEN & $22.8^{a}$ & $19.6 / 25.3$ & $p=0.0029$ & $12.9^{a}$ & $10.8 / 15.4$ \\
\hline PAN & $18.6^{\mathrm{ab}}$ & $16.3 / 20.0$ & $p=0.6022$ & $14.2^{\mathrm{a}}$ & $11.0 / 16.1$ \\
\hline RXU & $16.7^{b}$ & $13.7 / 17.3$ & $p=1.0000$ & $13.7^{a}$ & $10.8 / 15.2$ \\
\hline \multicolumn{6}{|c|}{ Leucite-reinforced feldspathic ceramic } \\
\hline VAR & $29.9^{a}$ & $26.5 / 31.0$ & $p=0.0029$ & $12.0^{a}$ & $11.1 / 12.8$ \\
\hline ARC & $27.3^{\mathrm{ab}}$ & $23.3 / 31.3$ & $p=0.0070$ & $11.2^{a}$ & $9.9 / 13.9$ \\
\hline PAN & $20.4^{b}$ & $18.7 / 21.9$ & $p=0.0161$ & $13.2^{a}$ & $12.8 / 14.4$ \\
\hline RXU & $10.5^{c}$ & $9.4 / 14.2$ & $p=0.3381$ & $16.4^{\mathrm{a}}$ & $11.0 / 21.6$ \\
\hline \multicolumn{6}{|c|}{ Densely sintered aluminum-oxide ceramic } \\
\hline PAN & $19.8^{\circ}$ & $17.0 / 25.0$ & $p=0.9358$ & $16.2^{a}$ & $8.1 / 21.2$ \\
\hline ARC & $16.8^{a}$ & $15.5 / 18.8$ & $p=0.0012$ & $0.0^{\mathrm{b}}$ & $0.0 / 6.4$ \\
\hline$R X U$ & $12.0^{\mathrm{b}}$ & $10.3 / 14.8$ & $p=0.0016$ & $2.6^{\mathrm{ab}}$ & $1.5 / 3.5$ \\
\hline
\end{tabular}

VAR: Variolink II, VEN: RelyX Veneer, ARC: RelyX ARC, PAN: Panavia F, RXU: RelyX Unicem. Early SBS: specimens aged in distilled water for 3 days prior SBS testing, Late SBS: Specimens subjected to 12,000 thermocycles prior SBS testing. Identical superscript letters indicate that the values are not significantly different within groups, within columns $(p>0.05)$.

surface. Specimens then were treated according to their respective group. The feldspathic ceramic and leucite-reinforced feldspathic ceramic specimens were etched with $4.8 \%$ hydrofluoric acid for $2 \mathrm{~min}$. The densely sintered aluminum-oxide ceramic specimens were airborne particle abraded with $50 \mu \mathrm{m} \mathrm{Al}_{2} \mathrm{O}_{3}$ at a pressure of 2.5 bar and from a distance of $10-\mathrm{mm}$ for $12 \mathrm{~s}$. Specimens then were cleaned ultrasonically in isopropyl alcohol for $3 \mathrm{~min}$, rinsed, and stored in distilled water until use.

Composite resin cylinders (Z100, 3M ESPE) serve as the substrate to be cemented to the ceramic specimens. They were made using an acrylic tube with an inner diameter of $2.9 \mathrm{~mm}$ and height of 3.0$\mathrm{mm}$, and light-cured for $40 \mathrm{~s}$ from the top and two sides for a total of $120 \mathrm{~s}$. The Coltolux 4 (Coltène, Whaledent, Mahwah,

USA) light-curing unit was used with its intensity being measured using the Coltolux 4 light meter to ensure adequate output (above $450 \mathrm{~mW} / \mathrm{cm}^{2}$ ).

Five minutes after light curing, the composite resin cylinders were cemented to the treated ceramic specimens. The cements were used with their respective bonding/silane coupling agent and applied according to the manufacturers' recommendations
(Table 1). Cementation procedures were performed with the aid of an alignment apparatus consisting of parallel guides, a holder for the composite resin cylinder, and an added weight of 1,000 g. The setup ensured that the axis of the composite resin specimen was perpendicular to the surface of the ceramic specimen and that a uniform layer of resin cement was used. Specimens were placed in the alignment apparatus and a load of 1,000 $\mathrm{g}$ was applied for $10 \mathrm{~min} .{ }^{6}$ Excess cement was removed with the use of foam pellets (Disposable MiniSponge Applicators, 3M ESPE) and microbrushes (Microbrush International, Grafton,

USA). Materials were light-cured for $40 \mathrm{~s}$ from three sides for a total of $120 \mathrm{~s}$. In the Panavia F (PAN) group, the oxygen-blocking gel Oxyguard II (Kuraray Medical Inc., Tokyo, Japan) was applied at the margins prior to light-curing procedures. After $10 \mathrm{~min}$, specimens were removed from the alignment device and stored in distilled water. Half of the specimens (10/group) were tested in SBS after 3 days (early SBS) while the other half was thermocycled. Thermocycling consisted of a total of 12,000 cycles between 5 and $60^{\circ} \mathrm{C}$ with a dwell time of $15 \mathrm{~s}$. Two thousand cycles were repeated every 30 days (total 
of 180 days) as a method of stressing the bonding interface (late SBS).

After aging, specimens were tested in shear with the aid with a chisel-knife ${ }^{31}$ using an Instron 4441 (Instron Corp., Norwood,

USA). Crosshead load speed was set at $1 \mathrm{~mm} / \mathrm{min}$. Results were expressed in MPa and calculated by dividing the failure load $(\mathrm{N})$ by the bonding area $\left(\mathrm{mm}^{2}\right)$. To assess failure mode, all specimens were examined with a light microscope at $25 \mathrm{X}$ magnification. Failure mode was categorized as cohesive in ceramic (CCe), cohesive in composite resin (CCo), and adhesive (Ad).

A review of the literature on ceramic bonding revealed that a sample size of 6 to 10 specimens per group is commonly used. The data of study similar to the present study was used for power analysis, which indicated that a sample size of 4 specimens per group would be sufficient to achieve $90 \%$ power in detecting differences between group means at least as large as observed in that study. ${ }^{6}$ Therefore a sample size of 10 specimens per group was adequate to provide sufficient power (more than 99\%).

Statistical analysis compared the SBS among substrates and among cements within each substrate. Since a small number of 10 disks were assigned for each group and normal assumption was violated, Kruskal-Wallis tests were used to test the SBS among substrates; among cements within each substrate; and for both pre- and post-thermocycling groups. Mann-Whitney tests with Bonferroni correction were then conducted to compare substrates and cements pairwisely. The significance level was set at 0.05 and all analyses were performed using SAS 9.3 (Cary, USA).

\section{Results}

Medians, $25^{\text {th }}$ and $75^{\text {th }}$ percentiles of SBS values in $\mathrm{MPa}$ are listed in Table 2. Shear bond strength values are illustrated in Figures 1-3. Based on the Kruskal-Wallis tests, MPa values were significantly different among substrates ( $p<0.05)$; and among resin cements within feldspathic ceramic $(p<0.05)$, leucite-reinforced feldspathic ceramic $(p<0.05)$, and densely sintered aluminum-oxide ceramic $(p<0.05)$. The results of the Mann-Whitney tests showed no differences between feldspathic ceramic and leucite-reinforced feldspathic ceramic $(\mathrm{p}>0.05)$. There were differences between feldspathic ceramic and densely sintered aluminum-oxide ceramic ( $p$ $<0.05$ ); and between leucite-reinforced feldspathic ceramic and densely sintered aluminum-oxide ceramic $(p<0.05)$.

The fracture analysis revealed different failure patterns among groups. The percentage distribution of the predominant failure mode for each group is presented in Table 3.

Feldspathic ceramic

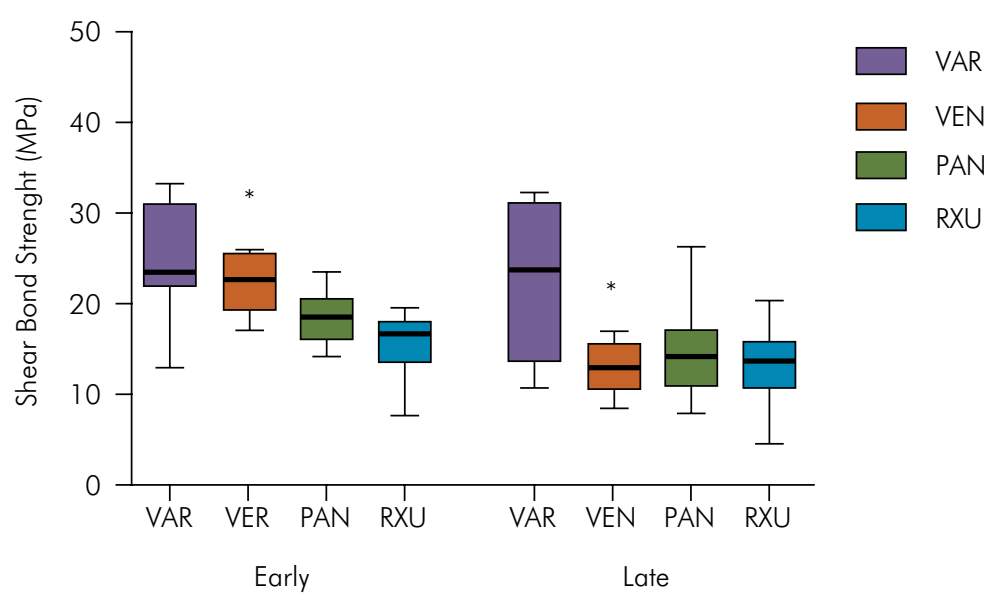

Figure 1. Boxplots of early and late shear bond strength of resin cements to feldspathic ceramic. 
Leucite-reinforced feldspathic ceramic

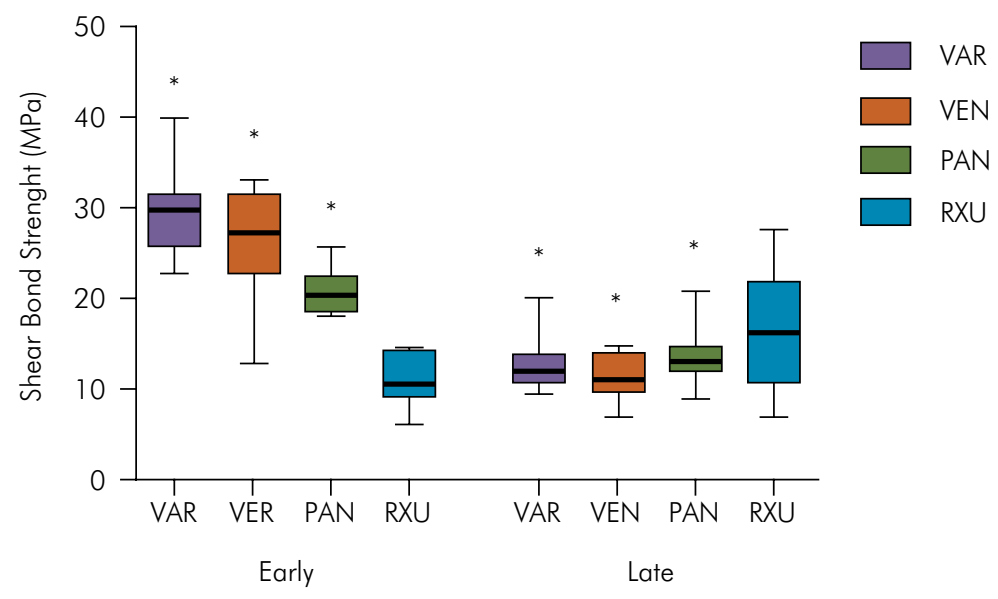

Figure 2. Boxplots of early and late shear bond strength of resin cements to leucite-reinforced feldspathic ceramic.

Densely sintered aluminum-oxide ceramic

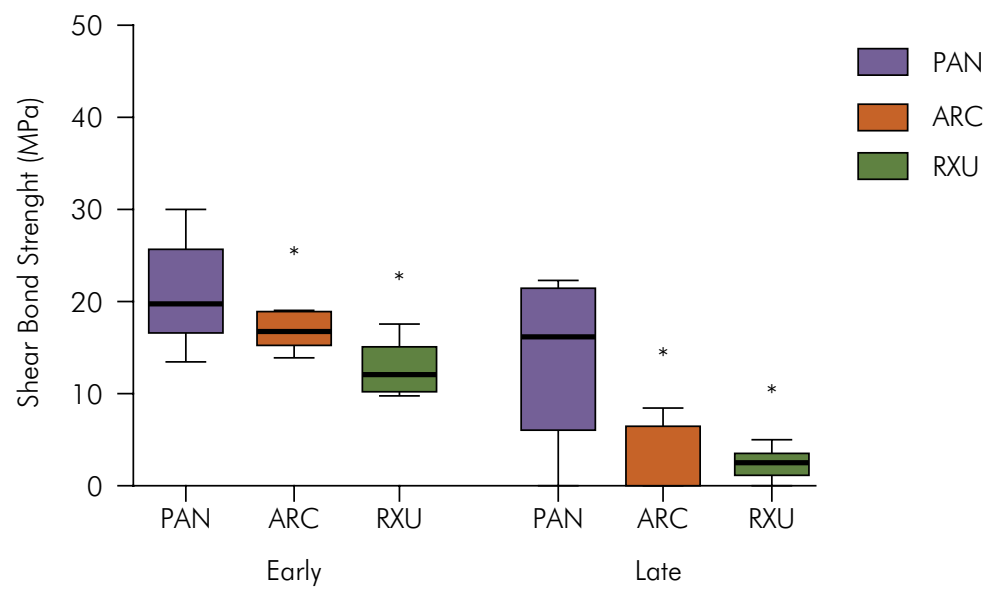

Figure 3. Boxplots of early and late shear bond strength of resin cements to densely sintered aluminum-oxide ceramic.

Table 3. Percentage distribution of failure modes per ceramic group.

\begin{tabular}{|c|c|c|c|c|c|c|c|c|c|c|c|}
\hline \multirow{2}{*}{ Variable } & \multicolumn{4}{|c|}{ Feldspathic } & \multicolumn{4}{|c|}{ Leucite-reinforced feldspathic } & \multicolumn{3}{|c|}{ Densely sintered aluminum-oxide } \\
\hline & VAR & VEN & PAN & RXU & VAR & ARC & PAN & RXU & PAN & ARC & RXU \\
\hline Non-thermocycled & $\begin{array}{l}100 \% \\
\mathrm{CCe}\end{array}$ & $\begin{array}{l}100 \% \\
\mathrm{CCe}\end{array}$ & $\begin{array}{l}100 \% \\
\mathrm{CCe}\end{array}$ & $\begin{array}{l}100 \% \\
\mathrm{CCe}\end{array}$ & $\begin{array}{l}100 \% \\
\mathrm{CCe}\end{array}$ & $\begin{array}{l}100 \% \\
\mathrm{CCe}\end{array}$ & $\begin{array}{l}100 \% \\
\mathrm{CCe}\end{array}$ & $\begin{array}{l}100 \% \\
\mathrm{CCe}\end{array}$ & $\begin{array}{c}100 \% \\
\mathrm{Ad}\end{array}$ & $\begin{array}{c}100 \% \\
\mathrm{Ad}\end{array}$ & $\begin{array}{c}100 \% \\
\mathrm{Ad}\end{array}$ \\
\hline Thermocycled & $\begin{array}{l}75 \% \\
\mathrm{CCe}\end{array}$ & $\begin{array}{l}13 \% \\
\mathrm{CCe}\end{array}$ & $\begin{array}{l}31 \% \\
\mathrm{CCe}\end{array}$ & $\begin{array}{l}21 \% \\
\mathrm{CCe}\end{array}$ & $\begin{array}{l}16 \% \\
\mathrm{CCe}\end{array}$ & $\begin{array}{l}18 \% \\
\mathrm{CCe}\end{array}$ & $\begin{array}{l}29 \% \\
\mathrm{CCe}\end{array}$ & $\begin{array}{l}37 \% \\
\mathrm{CCe}\end{array}$ & $\begin{array}{c}3 \% \\
\text { CCo }\end{array}$ & $\begin{array}{c}100 \% \\
\mathrm{Ad}\end{array}$ & $\begin{array}{c}100 \% \\
\mathrm{Ad}\end{array}$ \\
\hline
\end{tabular}

VAR: Variolink II, VEN: RelyX Veneer, ARC: RelyX ARC, PAN: Panavia F, RXU: RelyX Unicem. CCe: cohesive fracture in the ceramic, Ad: adhesive failure along bonded interface, CCo: cohesive in composite.

\section{Discussion}

The results of the present study showed significant differences in bond strength values among the different ceramicsand resincements, beforeand after thermocycling, which led to rejection of the null hypothesis.

In the non-thermocycled groups, bond strengths of RelyX Unicem (RXU) to all test ceramics were the 
lowest. That was not statistically significantly different from PAN in the feldspathic ceramic group. The worse overall (early) bonding performance of RXU might be attributed to its high viscosity or weight percentage of fillers (wt \%), which may affect its wetting and infiltrating abilities. ${ }^{32}$ Despite the lower early SBS for RXU, the results obtained for this resin cement may be considered acceptable as 10-13 MPa is considered the minimum needed for clinical bonding. ${ }^{33}$

Regarding the densely sintered aluminum-oxide ceramic group, the resin cement PAN demonstrated bond strength values greater than that of the other resin cements (not statistically different from ARC). The phosphate ester monomer 10-MDP may have helped creating better bonds to airborne particle abraded densely sintered aluminum-oxide ceramic ${ }^{34}$ by chemical interaction with the oxide layer present on the ceramic surface. ${ }^{29}$ The phosphoric-acid methacrylates contained in RXU, which have been shown to provide a "physical interaction" with the airborne-particle-abraded ceramic surface ${ }^{35,36}$ resulted in SBS that were approximately $60 \%$ of that of PAN (12.0 MPa vs. 19.8 MPa, respectively).

To evaluate the influence of aging on bond strength stability, a stress test comprising cyclic thermal fluctuations (thermocycling) is often carried out. ${ }^{6,27,29,37}$ Thermocycling utilizes differences in thermal coefficients of expansion of the ceramic and resin cements to stress the adhesive interface, which has its resistance to hydrolytic degradation challenged by water storage. ${ }^{37}$ Long-term water storage along with thermocycling $(12,000$ cycles performed over 180 days) exhibited no impact on SBS for some of the test resin cements. While the aging methodology might have exposed the adhesive interface to hydrolysis and consequently weakened the adhesion for some test materials, it showed a tendency to increase the bond strength of RXU to leucite-reinforced feldspathic ceramic (not statistically significantly different).

Another interesting finding of this study was the reduction in bond strengths for ARC when bonded to the densely sintered aluminum-oxide ceramic from 16.8 MPa (early SBS) to $0 \mathrm{MPa}$ (late SBS). The late (lack of) bond strength resulted in most specimens debonding spontaneously before testing. Similarly, specimens bonded with RXU to the same ceramic surface showed low late SBS of 2.6 MPa after early SBS of 12.0. In contrast, PAN showed stable SBS after thermocycling. The functional monomer 10-MDP may have promoted stable micromechanical and chemical bonds creating a long-term durable bond for PAN. 6,29,36 The results for the densely sintered aluminum-oxide ceramic are in partial agreement with a study by Piwowarczyk and colleagues ${ }^{27}$ that demonstrated better bonding of PAN than ARC to Procera AllCeram. Differently from the present study, however, RXU showed an increase in SBS over time. The much shorter aging process in that project may explain the difference in results.

In the feldspathic ceramic group, RelyX Veneer (VEN) was the only resin cement to show decrease in SBS after aging with $87 \%$ of the failures being adhesive. Water storage has shown detrimental effects (hydrolytic degradation) at the VEN/feldsphatic ceramic interface, despite the pretreatment with silane and hydrofluoric acid. ${ }^{38}$ The present study also showed decreased SBS for VAR, ARC, and PAN after artificial aging in the leucite-reinforced feldspathic ceramic group, while RXU showed a slight increase in median SBS (not statistically significant). The overall decrease in SBS in the leucite-reinforced feldspathic ceramic group may be due to weakening of the ceramic substrate. ${ }^{39}$

Another important indicator of the quality of the adhesive interface is the analysis of fracture modes. The $100 \%$ cohesive failures in ceramic for the feldspathic and leucite-reinforced feldspathic ceramic groups suggests that the bonded interface was stronger than those ceramics themselves when tested prior to thermocycling. The pattern somewhat changed once the specimens were thermocycled with cohesive failures (either in ceramic or composite) being noticed. On the other hand, adhesive failures ( $100 \%$ of cases) were observed in the densely sintered aluminum-oxide ceramic samples at baseline. This can be explained by the fact that oxide ceramics have flexural resistance higher than the other test ceramics. ${ }^{31}$ It is evident that the SBS of resin cements to ceramics is decreased by thermocycling, yet, surprising was the high spontaneous debonding rate for ARC and RXU after thermocycling in the densely sintered aluminum-oxide group. 
The clinical relevance of bond strength tests is often questioned because of the limitations of the tests available. Moreover, comparison between studies may be challenging as different methods will result in different failure modes, for instance. $6,18,23,34,40,41,42,43,44$ Yet, their value as screening tools for determination of the potential of resin cements, in the case of the present study, in the clinical setting should not be ignored. In that regard, the shear bond strength test has been widely applied to compare ceramics despite some researchers preferring modified tensile tests in order to eliminate the occurrence of non uniform interfacial stresses. They are typically present in conventional tensile and shear bond strength tests. Non uniform distribution of stress may result in an excessive number of cohesive failures in the ceramic substrate ${ }^{45}$ which compromises data interpretation. Controlled clinical trials are ideal to test specific treatment modalities and their long-term durability. However, in vitro investigations are indispensable to identify superior materials before their clinical evaluation, especially for comparative studies of bonding agents and cements. Additional in vitro and clinical research is necessary before investigators can make detailed recommendations on bonding methods to ceramic restorations.

In regards to the several of the failures occurring within the ceramic substrate in the present study, cohesive failures should be expected for weaker ceramic substrates with the standard shear bond strength test methods. Indeed, failure modes were predominantly cohesive within the ceramic for the silica-based ceramics. This fact, combined with the varying and non-axial forces applied in the standard shear bond strength test, indicates that shear bond strengths are greater than inherent strength of the material and, indeed, question the validity of the test set up. However, the applied set up with a shear load applied at the bonding interface through a chisel is by far the most common bond strength test in dental material science and, at the very least, allows direct comparisons between materials and also with other studies.

\section{Conclusions}

Within the limitations of this study, we concluded that resin cements perform differently when bonded to different ceramic substrates. While all test resin cements worked similarly in the long-term to feldspathic and leucite-reinforced feldspathic ceramics, only the 10-MDP-containing resin cement provided durable bonds to densely sintered aluminum-oxide ceramic.

\section{Acknowledgements}

The work in this manuscript was performed in partial fulfillment of requirements for $\mathrm{PhD}$ degree. David Farias was PhD candidate at the Universidade Federal de Santa Catarina and completed the studies at the University of Pennsylvania.

\section{References}

1. Donovan TE, Chee WW. Conservative indirect restorations for posterior teeth. Cast versus bonded ceramic. Dent Clin North Am. 1993 Jul;37(3):433-43.

2. el-Mowafy O. The use of resin cements in restorative dentistry to overcome retention problems. J Can Dent Assoc. 2001 Feb;67(2):97-102.

3. Sorensen JA, Kang SK, Avera SP. Porcelain-composite interface microleakage with various porcelain surface treatments. Dent Mater. 1991 Apr;7(2):118-23. https://doi.org/10.1016/0109-5641(91)90057-6

4. Jensen ME, Sheth JJ, Tolliver D. Etched-porcelain resin-bonded full-veneer crowns: in vitro fracture resistance. Compendium. 1989;10(6):336-8, 40-1, 44-7.

5. Blatz MB, Sadan A, Kern M. Resin-ceramic bonding: a review of the literature. J Prosthet Dent. 2003 Mar;89(3):268-74. https://doi.org/10.1067/mpr.2003.50

6. Kern M, Thompson VP. Bonding to glass infiltrated alumina ceramic: adhesive methods and their durability. J Prosthet Dent. 1995 Mar;73(3):240-9. https://doi.org/10.1016/S0022-3913(05)80200-8

7. Sadan A, Blatz MB, Soignet D. Influence of silanization on early bond strength to sandblasted densely sintered alumina. Quintessence Int. 2003 Mar;34(3):172-6 
8. Yen TW, Blackman RB, Baez RJ. Effect of acid etching on the flexural strength of a feldspathic porcelain and a castable glass ceramic. J Prosthet Dent. 1993 Sep;70(3):224-33. https://doi.org/10.1016/0022-3913(93)90056-T

9. Höland W, Schweiger M, Frank M, Rheinberger V. A comparison of the microstructure and properties of the IPS Empress 2 and the IPS Empress glass-ceramics. J Biomed Mater Res. 2000;53(4):297-303. https://doi.org/10.1002/1097-4636(2000)53:4<297::AID-JBM 3>3.0.CO;2-G

10. Söderholm KJ. Influence of silane treatment and filler fraction on thermal expansion of composite resins. J Dent Res. 1984 Nov;63(11):1321-6. https://doi.org/10.1177/00220345840630111401

11. Barghi N, Fischer DE, Vatani L. Effects of porcelain leucite content, types of etchants, and etching time on porcelain-composite bond. J Esthet Restor Dent. 2006;18(1):47-52. https://doi.org/10.2310/6130.2006.00001

12. Amaral R, Ozcan M, Bottino MA, Valandro LF. Microtensile bond strength of a resin cement to glass infiltrated zirconia-reinforced ceramic: the effect of surface conditioning. Dent Mater. 2006 Mar;22(3):283-90. https://doi.org/10.1016/j.dental.2005.04.021

13. Jevnikar P, Krnel K, Kocjan A, Funduk N, Kosmac T. The effect of nano-structured alumina coating on resin-bond strength to zirconia ceramics. Dent Mater. 2010 Jul;26(7):688-96. https://doi.org/10.1016/i.dental.2010.03.013

14. Valandro LF, Ozcan M, Bottino MC, Bottino MA, Scotti R, Bona AD. Bond strength of a resin cement to high-alumina and zirconia-reinforced ceramics: the effect of surface conditioning. J Adhes Dent. 2006 Jun;8(3):175-81.

15. Azimian F, Klosa K, Kern M. Evaluation of a new universal primer for ceramics and alloys. J Adhes Dent. 2012 Jun;14(3):275-82. https://doi.org/10.3290/i.jad.a22193

16. Seghi RR, Denry IL, Rosenstiel SF. Relative fracture toughness and hardness of new dental ceramics. J Prosthet Dent. 1995 Aug;74(2):145-50. https://doi.org/10.1016/S0022-3913(05)80177-5

17. Ozcan M, Kerkdijk S, Valandro LF. Comparison of resin cement adhesion to Y-TZP ceramic following manufacturers' instructions of the cements only. Clin Oral Investig. 2008 Sep;12(3):279-82. https://doi.org/10.1007/s00784-007-0151-y

18. Awliya W, Odén A, Yaman P, Dennison JB, Razzoog ME. Shear bond strength of a resin cement to densely sintered high-purity alumina with various surface conditions. Acta Odontol Scand. 1998 Feb;56(1):9-13. https://doi.org/10.1080/000163598422992

19. Zhang Y, Lawn BR, Rekow ED, Thompson VP. Effect of sandblasting on the long-term performance of dental ceramics. J Biomed Mater Res B Appl Biomater. 2004 Nov;71(2):381-6. https://doi.org/10.1002/ibm.b.30097

20. Ozcan M, Vallittu PK. Effect of surface conditioning methods on the bond strength of luting cement to ceramics. Dent Mater. 2003 Dec;19(8):725-31. https://doi.org/10.1016/S0109-5641(03)00019-8

21. Valandro LF, Della Bona A, Antonio Bottino M, Neisser MP. The effect of ceramic surface treatment on bonding to densely sintered alumina ceramic. J Prosthet Dent. 2005 Mar;93(3):253-9. https://doi.org/10.1016/i.prosdent.2004.12.002

22. Peutzfeldt A, Asmussen E. Silicoating: evaluation of a new method of bonding composite resin to metal. Scand J Dent Res. 1988 Apr;96(2):171-6. https://doi.org/10.1111/j.1600-0722.1988.tb01425.x

23. Sadoun M, Asmussen E. Bonding of resin cements to an aluminous ceramic: a new surface treatment. Dent Mater. 1994 May;10(3):185-9. https://doi.org/10.1016/0109-5641(94)90030-2

24. Attia A. Bond strength of three luting agents to zirconia ceramic - influence of surface treatment and thermocycling. J Appl Oral Sci. 2011 Aug;19(4):388-95. https://doi.org/10.1590/S1678-77572011005000015

25. Blatz MB. Long-term clinical success of all-ceramic posterior restorations. Quintessence Int. 2002 Jun;33(6):415-26.

26. Gerth HU, Dammaschke T, Züchner H, Schäfer E. Chemical analysis and bonding reaction of RelyX Unicem and Bifix compositesa comparative study. Dent Mater. 2006 Oct;22(10):934-41. https://doi.org/10.1016/i.dental.2005.10.004

27. Piwowarczyk A, Laver HC, Sorensen JA. In vitro shear bond strength of cementing agents to fixed prosthodontic restorative materials. J Prosthet Dent. 2004 Sep;92(3):265-73. https://doi.org/10.1016/i.prosdent.2004.06.027

28. Borges GA, de Goes MF, Platt JA, Moore K, de Menezes FH, Vedovato E. Extrusion shear strength between an alumina-based ceramic and three different cements. J Prosthet Dent. 2007 Sep;98(3):208-15. https://doi.org/10.1016/S0022-3913(07)60057-2

29. Blatz MB, Sadan A, Soignet D, Blatz U, Mercante D, Chiche G. Long-term resin bond to densely sintered aluminum oxide ceramic. J Esthet Restor Dent. 2003;15(6):362-8. https://doi.org/10.1111/j.1708-8240.2003.tb00309.x

30. Kumbuloglu O, Lassila LV, User A, Toksavul S, Vallittu PK. Shear bond strength of composite resin cements to lithium disilicate ceramics. J Oral Rehabil. 2005 Feb;32(2):128-33. https://doi.org/10.1111/j.1365-2842.2004.01400.x

31. Blatz MB, Sadan A, Arch GH r, Lang BR. In vitro evaluation of long-term bonding of Procera AllCeram alumina restorations with a modified resin luting agent. J Prosthet Dent. 2003 Apr;89(4):381-7. https://doi.org/10.1067/mpr.2003.89

32. Han L, Okamoto A, Fukushima M, Okiji T. Evaluation of physical properties and surface degradation of self-adhesive resin cements. Dent Mater J. 2007 Nov;26(6):906-14. https://doi.org/10.4012/dmi.26.906

33. Thurmond JW, Barkmeier WW, Wilwerding TM. Effect of porcelain surface treatments on bond strengths of composite resin bonded to porcelain. J Prosthet Dent. 1994 Oct;72(4):355-9. https://doi.org/10.1016/0022-3913(94)90553-3

34. Blixt M, Adamczak E, Lindén LA, Odén A, Arvidson K. Bonding to densely sintered alumina surfaces: effect of sandblasting and silica coating on shear bond strength of luting cements. Int J Prosthodont. 2000 May-Jun;13(3):221-6. 
35. Friederich R, Kern M. Resin bond strength to densely sintered alumina ceramic. Int J Prosthodont. 2002 Jul-Aug;15(4):333-8.

36. Yoshida K, Tsuo Y, Atsuta M. Bonding of dual-cured resin cement to zirconia ceramic using phosphate acid ester monomer and zirconate coupler. J Biomed Mater Res B Appl Biomater. 2006 Apr;77(1):28-33. https://doi.org/10.1002/jbm.b.30424

37. Peumans M, Hikita K, De Munck J, Van Landuyt K, Poitevin A, Lambrechts P, et al. Bond durability of composite luting agents to ceramic when exposed to long-term thermocycling. Oper Dent. 2007 Jul-Aug;32(4):372-9. https://doi.org/10.2341/06-106

38. Piwowarczyk A, Laver HC. Mechanical properties of luting cements after water storage. Oper Dent. 2003 Sep-Oct;28(5):535-42.

39. Blatz MB, Sadan A, Maltezos C, Blatz U, Mercante D, Burgess JO. In vitro durability of the resin bond to feldspathic ceramics. Am J Dent. 2004 Jun;17(3):169-72.

40. Kern M, Wegner SM. Bonding to zirconia ceramic: adhesion methods and their durability. Dent Mater. 1998 Jan;14(1):64-71. https://doi.org/10.1016/S0109-5641(98)00011-6

41. Madani M, Chu FC, McDonald AV, Smales RJ. Effects of surface treatments on shear bond strengths between a resin cement and an alumina core. J Prosthet Dent. 2000 Jun;83(6):644-7. https://doi.org/10.1067/mpr.2000.107337

42. Wegner SM, Kern M. Long-term resin bond strength to zirconia ceramic. J Adhes Dent. 2000;2(2):139-47.

43. Ozcan M, Alkumru HN, Gemalmaz D. The effect of surface treatment on the shear bond strength of luting cement to a glass-infiltrated alumina ceramic. Int J Prosthodont. 2001 Jul-Aug;14(4):335-9.

44. Wegner SM, Gerdes W, Kern M. Effect of different artificial aging conditions on ceramic-composite bond strength. Int J Prosthodont. 2002 May-Jun;15(3):267-72.

45. Chadwick RG, Mason AG, Sharp W. Attempted evaluation of three porcelain repair systems:what are we really testing? J Oral Rehabil. 1998 Aug;25(8):610-5. https://doi.org/10.1046/j.1365-2842.1998.00283.x 